\title{
The Oxford Handbook of Applied Ethnomusicology
}

The Oxford Handbook of Applied Ethnomusicology. Uredila Svanibor Pettan in Jeff Todd Titon. Oxford: Oxford University Press, 2015.864 str. 97 £. ISBN: 9780199351701.

V juliju 2015 je založba Oxford University Press izdala obsežno knjigo z naslovom The Oxford Handbook of Applied Ethnomusicology (Oxfordov priročnik aplikativne muzikologije), ki sta jo uredila dva ugledna etnomuzikologa, Svanibor Pettan in Jeff Todd Titon. Knjiga je impresivna zbirka različnih pristopov v aplikativni etnomuzikologiji, ki so jih razvili s kombinacijo etnografskega raziskovanja (osebnih izkušenj in terenskega dela v različnih delih sveta) in sodobne znanosti. Knjiga obsega uvod in dvaindvajset poglavij, razdeljenih v šest tematskih delov. Začetni del, Uvod v aplikativno etnomuzikologijo, vsebuje uvod in tri podrobnejša poglavja izpod peres urednikov: Aplikativna etnomuzikologija: opisna in historična pripoved avtorja Jeffa Todda Titona podaja pomemben pregled zgodovinskega razvoja etnomuzikologije, predvsem aplikativne etnomuzikologije v Ameriki, medtem ko Aplikativna etnomuzikologija v globalni areni avtorja Svaniborja Pettana oriše zgodovinski razvoj etnomuzikologije v Evropi s poudarkom na vlogi Mednarodnega sveta za tradicionalno glasbo (ICTM) kot najpomembnejšega mednarodnega etnomuzikološkega združenja pri oblikovanju različnih pristopov v aplikativni etnomuzikologiji. Na podlagi lastnih izkušenj Pettan poda dragoceno opredelitev aplikativne etnomuzikologije, ki je podkrepljena s posebno zanimivimi pogledi petih etnomuzikologov iz Afrike, Avstralije, Azije, Evrope in Južne Amerike o morebitni vlogi etnomuzikologije v izobraževanju.

Protiutež izčrpnemu uvodnemu delu so bolj specifične tematske struje v delih, ki obravnavajo teoretske in metodološke premisleke, zagovorništvo, domorodna ljudstva, konflikte, izobraževanje in agencije. Več avtorjev preučuje pristope k aplikativni etnomuzikologiji v kontekstu pomembnih vprašanj o kolonialni zgodovini in pogledih. Dan Bendrups, Klisala Harrison, Tan Sooi Beng, Zoe C. Sherinian, Elizabeth Mackinlay, Joshua D. Pilzer in John Morgan O'Connell opozarjajo bralca na različne kontekste in pristope, ki so pomembni za postkolonialne analize - naloge, ki zahtevajo posebno občutljivost s strani raziskovalcev (str. 56-57). Tako na primer O'Connell razvije zanimiv hermenevtični pristop do glasbene vzgoje s preučevanjem povezav med glasbo in ljudmi, ki izvira iz humanističnega izobraževalnega programa fundacije Aga Khan. V poglavju Kulturno udejstvovanje in lastništvo s pomočjo participativnih pristopov v aplikativni etnomuzikologiji avtorica Tan Sooi Beng temeljito preučuje načela opazovanja, ki so se pojavila s takoimenovanim "gledališčem za razvoj« v Aziji (str. 111), in razmišlja, kako bi lahko tovrstne pristope prepoznali na določenih področjih 
aplikativne etnomuzikologije, na primer pri organizaciji vsakoletnega praznovanja ljudskega izročila v mestu George Town (v malezijski zvezni državi Penang) od leta 2010 naprej, katerega osrednji cilj je bila obuditev multietične zgodovine in pobud za vzpostavitev miru. Politični podtoni se nadaljujejo v poglavjih avtorjev Zhanga Boyuja in Britte Sweers. Boyu ponuja dobrodošle poglede na aplikativno etnomuzikologijo na Kitajskem in s pomočjo analize kulturne politike na vseh ravneh vladnih struktur pokaže, kako ta vpliva na značilnosti aplikativne etnomuzikologije v državi. Nasprotno pa se Sweers v svojem poglavju Glasba in reševanje sporov osredotoči na tri različne študije primerov v Nemčiji in Švici (takoimenovana "akcijska etnomuzikologija«), ki dajejo pomemben vpogled $\mathrm{v}$ migracijo in aktualna vprašanja o funkciji in javnem predstavljanju manjšin v sodobnem svetu. Omenjene pristope izravna poglavje avtorja Dana Lundberga, ki poudarja pomen arhivskega gradiva, zbranega izven akademskih krogov, in neposredni stik s skupnostjo kot tudi vlogo Komisije za ljudsko glasbo (FMC) pri zbiranju in ocenjevanju različnih glasbenih oblik. Po Lundbergovem mnenju je FMC »ustvarila jasen in razločen repertoar za bodoče generacije - kanon za švedsko ljudsko glasbo«(str. 700), ki ga opisuje kot proces v štirih korakih: identifikacija, klasifikacija, standardizacija in simbolizacija kulturne dediščine.

Ta knjiga prav tako združuje vodilne ameriške učenjake, ki nudijo nove poglede na vrsto pomembnih tem. Jeff Todd Titon na primer v svojem poglavju Vzdržnost, odpornost in prilagodljivo upravljanje za aplikativno etnomuzikologijo obravnava vlogo etnomuzikologov pri ohranjanju narave, kulture in glasbe v Severni Ameriki. Jeffrey A. Summit črpa iz osebnih izkušenj v Ugandi, da bi pokazal, kako lahko dejavnosti etnomuzikologov sprožijo pobude za izgradnjo miru in medverski dialog (s ponazoritvijo gospodarskega sodelovanja med pridelovalci kave). Alan Williams proučuje, kako lahko aplikativna etnomuzikologija pomaga pri ustvarjanju družbenega in gospodarskega kapitala v nerazvitih skupnostih: njegovo poglavje preučuje, kako se tehnologija, mediji in trženje križajo, da bi ustvarili kulturni prostor, ki bi lahko spreminjal glasbene prakse v glasbene produkte (str. 772). Holly Wissler poizveduje o sodobnih izzivih turizma in preučuje projekte ohranjanja narave, ki so jih v odgovor na tovrstne izzive pripravile skupnosti andskih Q'erosov in amazonskih Wachiperijev, medtem ko Michael B. Bakan predlaga etnografske in relativistične pristope aplikativne etnomuzikologije kot alternativo obstoječim družbenim in zdravstvenim modelom pri obravnavi avtističnih oseb. Susan E. Oehler Herrick raziskuje strategije za uspešno integracijo aplikativne etnomuzikologije v osnovne in srednje šole (preko partnerstev z izobraževalnimi ustanovami, kulturnimi organizacijami in profesionalnimi glasbeniki). Podoben poudarek na angažiranju skupnosti zagovarjajo tudi drugi avtorji, vključno s Patricio Shehan Campbell in Leejem Higginsom, ki se osredotočata na povezovanje aplikativne etnomuzikologije in glasbene vzgoje (oboje v institucionalni obliki in znotraj skupnosti). Kot dodatek temu pa Clifford Murphy vidi etnomuzikologa kot javnega folklorista in preučuje disciplinarne vezi med aplikativno etnomuzikologijo in javno folkloro, kot so razvidne iz etnomuzikoloških praks ameriških državnih agencij.

Ob poglavjih, ki odpirajo bolj globalne poglede, bi predvsem rada opozorila še na dve poglavji, ki se nanašata na Bosno in Hercegovino. Ursula Hemetek v poglavju z naslovom Aplikativna etnomuzikologija kot medkulturni pripomoček: nekaj izkušenj 
iz raziskovanja manjšin v Avstriji v zadnjih 25 letih črpa iz svojega raziskovanja glasbe in manjšin (s poudarkom tako na zgodovinskem kot političnem kontekstu manjšinskih skupnosti v Avstriji), da bi preučevala vlogo aplikativne etnomuzikologije v posebnih manjšinskih skupnostih, kot so Romi, begunci iz Bosne in Hercegovine in priseljenci iz Turčije. Zlasti pa projekt Hemetkove prinaša dobrodošle nove poglede na javno podobo bosanskih beguncev - ponovno presojo, za katero si že dolgo prizadevajo sami begunci (str. 239) in ki kritično odpira diskurzivno področje za same bosanske etnomuzikologe. Podobno tudi Erica Haskell v svojem poglavju Vloga aplikativne etnomuzikologije v skupnostih po konfliktih in katastrofah črpa iz svojih izkušenj pri terenskem delu v Bosni in Hercegovini (vključno z njenim delom pri nevladni fundaciji Mozaik, ki je financirala razvoj skupnosti v vasi Guča Gora blizu Travnika). Njene študije primerov vključujejo skupino za ljudsko glasbo in ples Sloga, glasbene dogodke med obleganjem Sarajeva (1992-1995), Pavarotti center v Mostarju in delo založniške hiše Gramofon; vse to na novo osvetljuje povojni kulturni razvoj v Bosni in Hercegovini. Obe študiji razkrivata, kako je mogoče aplikativno etnomuzikologijo učinkovito uporabiti $\mathrm{v}$ določenih postkonfliktnih in manjšinskih kontekstih z namenom izboljšanja medsebojnega razumevanja.

Naj zaključim, da je knjiga The Oxford Handbook of Applied Ethnomusicology prevzela pomembno kulturno in izobraževalno nalogo s pomočjo poglavij, ki poizvedujejo o vlogi aplikativne etnomuzikologije v različnih življenjskih okoljih. Na ta način deluje kot razširitev knjige z naslovom Applied Ethnomusicology: Historical and Contemporary Approaches (Aplikativna etnomuzikologija: historični in sodobni pristopi), izdane v souredništvu leta 2010. Sodeluje večje število avtorjev, ki obravnavajo aplikativno etnomuzikologijo z različnimi pristopi. Na splošno se v knjigi zrcali prepričljiv obseg in kakovost znanstvenih pogledov: resnost pristopa in analize, dobro zasnovana struktura knjige ter dostopna besedila, namenjena širši mednarodni javnosti, skupaj tvorijo zelo dragoceno izdajo tako za strokovnjake kot študente, pa tudi za bralce $s$ področja drugih disciplin izven glasbe, kot sta npr. etnologija in kulturna antropologija.

Jasmina Talam,
Akademija za glasbo, Univerza v Sarajevu
Translated by Suzana Stančič

1 K. Harrison, E. Mackinlay in S. Pettan (ur.), Applied Ethnomusicology: Historical and Contemporary Approaches (Cambridge: Cambridge Scholars Publishing, 2010). 